\title{
A Planar Quasi-Yagi For Next Generation Wireless Communication Systems
}

\author{
Mai Thanh Nga ${ }^{1}$, Vu Van Yem ${ }^{1}$, Nguyen Huu Thanh ${ }^{1}$ and Pham Duy Phong ${ }^{2}$ \\ ${ }^{1}$ Faculty of Electronics and Telecommunications \\ Ha Noi University of Technology, No.1 Dai Co Viet road, Hai Ba Trung, Ha Noi, VIETNAM \\ ${ }^{2}$ Faculty of Electronics and Telecommunications, Electric Power University-VIETNAM \\ mainga91@gmail.com, yemw-fet@mail.hut.edu.vn, thanhnh-fet@mail.hut.edu.vn,phongphd@epu.edu.vn
}

\begin{abstract}
UMTS (Universal Mobile Telecommunications System) technology is one of the third-generation (3G) cell phone technologies, which is also being developed into a 4G technology. Although UMTS2001 is the most widelydeployed UMTS band, some countries utilize $1900 \mathrm{MHz}$ instead. Besides, the co-existing GPS (Global Positioning System) operates at the frequency of $1575 \mathrm{MHz}$. Thus, a desirable antenna in UMTS systems needs to cover both of two bands in order to operate in various devices. This paper will propound an antenna covering the range of frequencies from $1.53 \mathrm{GHz}$ to $2.53 \mathrm{GHz}$ that includes 1.575 GHz, $1.8 \mathrm{GHz}, 1.9 \mathrm{GHz}$, and $2.1 \mathrm{GHz}$. The developed quasi-Yagi antenna has a simple-low profile and achieves a bandwidth of $\mathbf{4 8 \%}$, a front- to- back ratio of $19 \mathrm{~dB}$, a gain of $6 \mathrm{dBi}$, and an efficiency of better than $78 \%$ at $2.1 \mathrm{GHz}$. In this paper, the study on effects of parameters of the antenna is also investigated to achieve optimal model.
\end{abstract}

Keyworlds: Quasi-Yagi antenna, Microstrip antenna, UMTS antenna, End-fire radiation pattern.

\section{INTRODUCTION}

Planar quasi-Yagi which was presented first by Qian et al is an excellent combination of radiation characteristic of a Yagi antenna and micro-strip technology [1]. Until now, various designs of the planar quasi-Yagi antennas with CPW-fed or micro-strip fed have been reported in the literature covering the $\mathrm{X}$-band [1]-[2]-[3], C band or $2.4 \mathrm{GHz}$ [4]. This kind of antenna has demonstrated both the compactness of resonanttype antennas and broadband characteristics of traveling-wave radiators [2]. However, most of previous research done on broadband antennas have been designing an antenna with high dielectric constant substrate materials [1]-[2]-[3]-[5]. Not much research has focused on designing and fabricating an antenna on a low dielectric constant substrate (the relative dielectric constant $\left.\varepsilon_{r}<5\right)$. Low dielectric substrate can bring a good result with a better radiation efficiency and larger bandwidth, even though at lower cost. Besides, while X-band has been in lots of research, UMTS band has not been focused equivalently to its potential. In addition, the detailed design of this antenna has not been shown yet in previous researchs. For these reasons, a planar antenna using material FR4 for UMTS and GPS applications will be introduced and characterized in deep in this paper. In addition, we investigate the effects of parameters of the antenna to come to the optimal model. In Section II, we present the antenna design. Optimization and simulation results of this antenna are shown in Section III. In Section IV, we introduce the antenna parameter study. Measurement result is presented in Section V. Finally, a brief conclusion is given in Section VI.

\section{ANTENNA DESIGN}

A schematic of an enhanced antenna is shown in Fig.1. As can be seen from Fig.1, this antenna is based on the structure of the classical Yagi-Uda one. It means that the antenna consists of a micro-strip feed, a broadband micro-strip-to-coplanar strip-line (CPS) or a balun, a driver element and a truncated ground on the backside. However, this enhanced antenna has two director elements and the parameters have been computed and refined to be appropriate to very wide desirable operation band that is not possible with classical ones. 


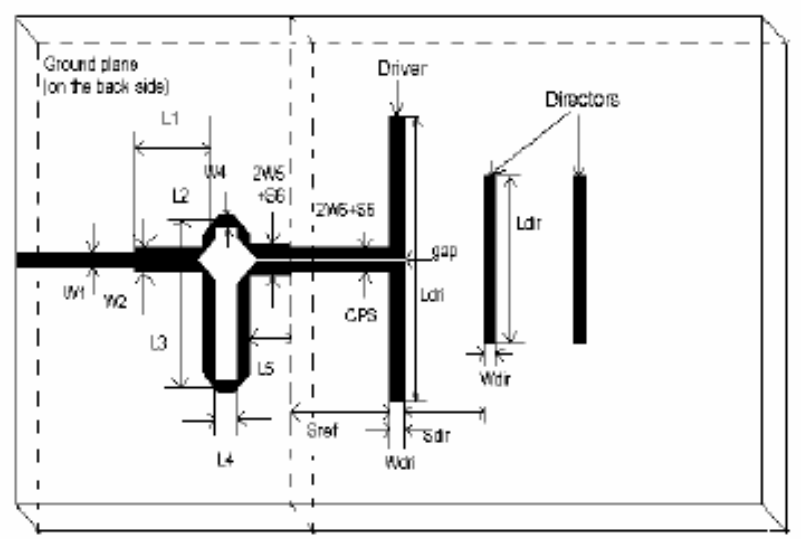

Fig.1- Schematic of the enhanced (2 directors) antenna

\section{A. The function of elements}

The truncated ground serves as a reflector element of the antenna. Two directors on the top of the plane being parasitic elements help the antenna to direct propagation toward the end-fire direction in order to increase the obtained gain and act as an impedancematching. However, they do not really affect the bandwidth as some research mentioned. A printed dipole called driver can generate a $\mathrm{TE}_{0}$ surface wave and very little undesired $\mathrm{TM}_{0}$ mode, which can contribute to cross polarization [6]. In the grounded area, there is a broadband balun that matches the CPS feeding the driver dipole to the mirco-strip access line. Specifically, this balun has two arms connecting to one quarter wavelength $\left(\lambda_{\mathrm{G}} / 4\right)$ transformer. The length of a left arm is $\lambda_{G} / 4$ smaller than a right arm to delay one side of micro-strip line by half wavelength at the designed frequency. As a result, it properly excites the odd mode of the CPS line.

\section{B. Design strategy}

When designing one antenna, we should focus on matched characteristics as return loss, radiation characteristics such as cross polarization, front-to-back ratio, and gain. Besides, another very important parameter is bandwidth defined to have both of two above characteristics. Indeed, to obtain expected results, the antenna's dimensions must be computed carefully, and then optimized. We have substrate's parameters as: $\mathrm{h}=1.6 \mathrm{~mm}$ (the thickness of the substrate),

$\varepsilon_{r}=4.8$ (the relative dielectric constant), the material loss $\tan \delta=0.02$ and the conducting thickness, $\mathrm{a}=0.035 \mathrm{~mm}$.

At first, before determining the antenna's specific dimensions, it is necessary to calculate the free-space wavelength $\lambda_{0}$ and the guide wavelength $\lambda_{\mathrm{G}}$.

Based on the equations from [5], we have:

Free-space wavelength $\lambda_{0}$

$$
\begin{gathered}
\lambda_{0}=\frac{c}{f}=\frac{3 \times 10^{8}}{2.1 \times 10^{9}}=142,8(\mathrm{~mm}) \\
H^{\prime}=\frac{Z_{0} \sqrt{2\left(\varepsilon_{r}+1\right)}}{120}+\frac{1}{2} \frac{\varepsilon_{r}-1}{\varepsilon_{r}+1}\left(\ln \frac{\pi}{2}+\frac{1}{\varepsilon_{r}} \ln \frac{4}{\pi}\right)
\end{gathered}
$$

Here $\mathrm{H}^{\prime}$ is an intermediate constant.

With $\varepsilon_{r}=4.8, Z_{0}=50 \Omega$, thus, $H^{\prime}=1.58(\mathrm{~mm})$

The calculation of the width-to-substrate thickness ratio of micro-strip feed is shown below:

$$
\frac{w}{h}=\frac{8 \times \exp \left(H^{\prime}\right)}{\exp \left(2 H^{\prime}\right)-2}=1.787(\mathrm{~mm})
$$

In respect to $\mathrm{h}=1.6 \mathrm{~mm}$, the width of $50 \Omega$ microstrip feed $w$ equals $2.86 \mathrm{~mm}$.

Besides, there is another way to determine this dimension easily by using free TxLine software. Therefore, it is very convenient to use this software to calculate the length of the gap between coupled microstrip lines. The obtained result $\mathrm{S}_{6}$ is $1 \mathrm{~mm}$.

Next, considering effective dielectric constant $\varepsilon_{\text {ff }}$ :

Due to $\mathrm{w} / \mathrm{h}>1$,

$$
\varepsilon_{\text {ff }}=\frac{\varepsilon_{r}+1}{2}+\frac{\varepsilon_{r}-1}{2}\left[\left(1+\frac{12}{w / h}\right)^{1 / 2}\right]=3.584
$$

After that, using this result to calculate the guide wavelength $\lambda_{\mathrm{G}}$ 


$$
\lambda_{G}=\frac{\lambda_{0}}{\sqrt{\varepsilon_{\text {ff }}}}=75.43(\mathrm{~mm})
$$

Initially, according to principles of designing a classical Yagi antenna [7], the length of the driver element should be around $0.5 \lambda_{0}$, while the lengths of two directors should be $0.4 \lambda_{0}$. The distance between the driver and the nearest director is optimized by $0.25 \lambda_{0}$, while the space between two adjacent directors is about $0.3 \lambda_{0}$.

Therefore, these primary dimensions can be: $L_{d i r}=57.12(\mathrm{~mm}), L_{d r i}=71.4(\mathrm{~mm}), S_{d i r}=35.7(\mathrm{~mm})$

The other dimensions can be determined as below:

$$
\begin{aligned}
& L_{2}=8.3(\mathrm{~mm}), L_{3}-L_{2}=18(\mathrm{~mm}), L_{4}=6(\mathrm{~mm}), \\
& L_{5}=10.3(\mathrm{~mm}) \\
& L_{\text {stripline }}=30(\mathrm{~mm}), W_{d r i}=2.86(\mathrm{~mm}) \\
& W_{4}=W_{\text {dri }}=W_{5}=w=2.86(\mathrm{~mm}), W_{6}=2(\mathrm{~mm})
\end{aligned}
$$

According to [5], the optimized distance between the driver and reflector is about a quarter guide wavelength

$$
S_{r e f}=\frac{\lambda_{G}}{4}=18(\mathrm{~mm})
$$

Because of the length of the quarter wavelength transformer,

$$
L_{1} \approx \frac{\lambda_{G}}{4}=18(\mathrm{~mm})
$$

Finally, to determine the size of the substrate, we can base on the experiment from [1]. The length $L$ is in the order of $\mathrm{L} \leq 0.6 \lambda_{0}$ and the width $\mathrm{W} \leq \lambda_{0} / 2$.

As a result, the two above dimensions will be initiated as follow:

$$
\begin{aligned}
& L=0.6 \lambda_{0}=85.68(\mathrm{~mm}) \\
& W=\frac{\lambda_{0}}{2}=71.4(\mathrm{~mm})
\end{aligned}
$$

Thus, all of dimensions of a quasi-Yagi antenna have been defined.

\section{OPTIMIZATION AND SIMULATION RESULTS}

\section{A. Optimization}

All simulations in this section as well as in Section IV are done using FDTD tool that is developed by our research group. The results obtained from simulation tool are exported to text format and then plotted by means of Matlab.

After lots of times of simulating and refining, we had a UMTS prototype quasi-Yagi with following dimensions:

$$
\begin{aligned}
& L_{d i r}=36(\mathrm{~mm}), L_{d r i}=60(\mathrm{~mm}), S_{d i r}=20(\mathrm{~mm}), \\
& W_{d r i}=4(\mathrm{~mm})
\end{aligned}
$$

$$
\begin{aligned}
L_{2}=8.3(\mathrm{~mm}), L_{3}-L_{2}=19(\mathrm{~mm}), L_{4}=6(\mathrm{~mm}), \\
L_{5}=10.3(\mathrm{~mm}) \\
\quad L_{\text {stripline }}=30(\mathrm{~mm}), S_{6}=1(\mathrm{~mm}), W_{6}=2(\mathrm{~mm}) \\
W_{4}=W_{\text {dir }}=W_{5}=W=2.86(\mathrm{~mm}), S_{\text {ref }}=25(\mathrm{~mm}) \\
L_{1}=17.5(\mathrm{~mm}), L=189(\mathrm{~mm}), W=104(\mathrm{~mm})
\end{aligned}
$$

Comparing to the theoretical dimensions of the previous section, there are a lot of changes. The final director element length $\boldsymbol{L}_{d r i}$ is shorter than the designed length, while the width of director $W_{d r i}$ was increased, which contributes to the antenna wideband characteristic. In addition, the final width $\mathrm{W}$ as well as the length of the substrate $\mathrm{L}$ was expanded to obtain a boarder bandwidth and degrade the return loss of the antenna. Other dimensions such as the difference between $\mathrm{L}_{3}$ and $\mathrm{L}_{2}, W_{\text {dir }}$, and $\mathrm{L}_{1}$ are close to get the optimum.

We will discuss the reasons of these rectifications in next section through analyzing the effect of each of dimensions on the operation of the antenna.

\section{B. Simulation results}

Figure 2 shows the simulated input return loss of the prototype antenna at the center $2.1 \mathrm{GHz}$ frequency. As can be seen from the figure, the antenna operates from 1.53 to $2.53 \mathrm{GHz}$ covering UMTS2100, and 1900 bands, as well as GPS1575 band. The highest level in the return loss graph reaches $-11.5 \mathrm{~dB}$, satisfying the condition of impedance matching, where the Voltage 
Standing Wave Ratio is smaller than 2 (VSWR $\leq 2$ ). The obtained bandwidth can be calculated as follows:



Fig. 2. Antenna input return loss

$$
B W=\frac{f_{\max }-f_{\min }}{f_{c}} \times 100 \%=\frac{2.53-1.53}{2.1} \times 100 \%=48 \%
$$

Here, $f_{\max }, f_{\min }$ are the maximum and minimum frequency, where $\left|\mathrm{S} 1 \_1\right|$ i.e. the input return loss of the antenna is smaller than $-10 \mathrm{~dB}$ corresponding to the VSWR $\leq 2 . f_{c}$ is the center frequency or the design frequency.



Fig.3. Antenna radiation pattern at $2.1 \mathrm{GHz}$
Figure 3 demonstrates the simulation result of farfield radiation pattern in E-plane at $2.1 \mathrm{GHz}$. We can see from this figure that the obtained radiation pattern of this antenna is good. There is no defect in the radiation pattern.

In Fig. 4, the gain of the antenna from 1.5 to 2.8 $\mathrm{GHz}$ is shown. Obviously, the increment of the gain is right proportion al to the increment of the operation frequency. At $2.1 \mathrm{GHz}$, the obtained gain is $6.2 \mathrm{dBi}$ with the radiation efficiency of $80 \%$. The gain of the antenna is decreased after $2.53 \mathrm{GHz}$ because it is not very well matched. In other word, it is out of operating frequency band.

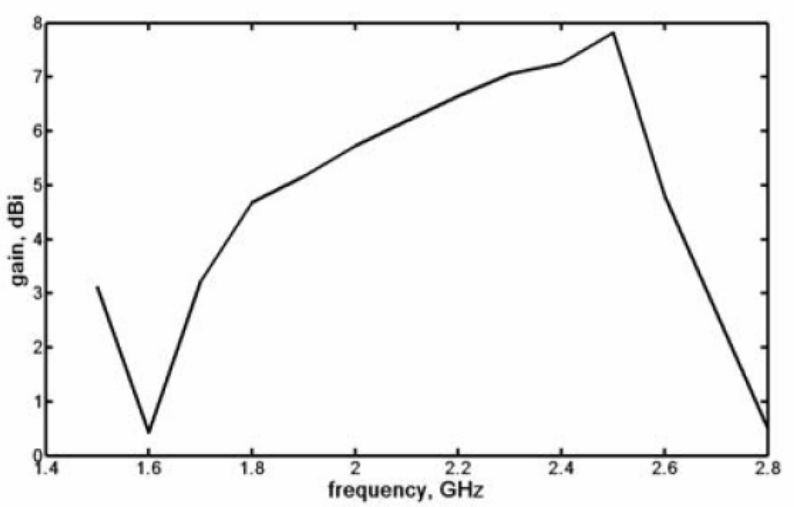

Fig.4. Gain of the designed antenna

\section{PARAMETER STUDY}

As mentioned in the previous section, quasi-Yagi antennas have several parameters, all of which have different influences in terms of operational frequency and bandwidth as well as radiation pattern. This research focuses on some main parameters, including Parameter 1 - the length of driver $\boldsymbol{L}_{\mathrm{d} r i}$, Parameter 2 the length of director $\boldsymbol{L}_{\text {dir }}$, Parameter 3 - the width of the gap $s_{6} ;$ Parameter 4 - the distance between director and the driver $\boldsymbol{S}_{\text {dim }}$ and Parameter 5 - the distance between director and the reflector $\boldsymbol{S}_{\text {ref }}$. Besides of these discussed parameters, we also considers $\boldsymbol{L}_{5}, \boldsymbol{L}_{4}$ as important parameters (Parameter 6 and Parameter 7 adequately). 
A. Parameter $1-L_{d r i}$

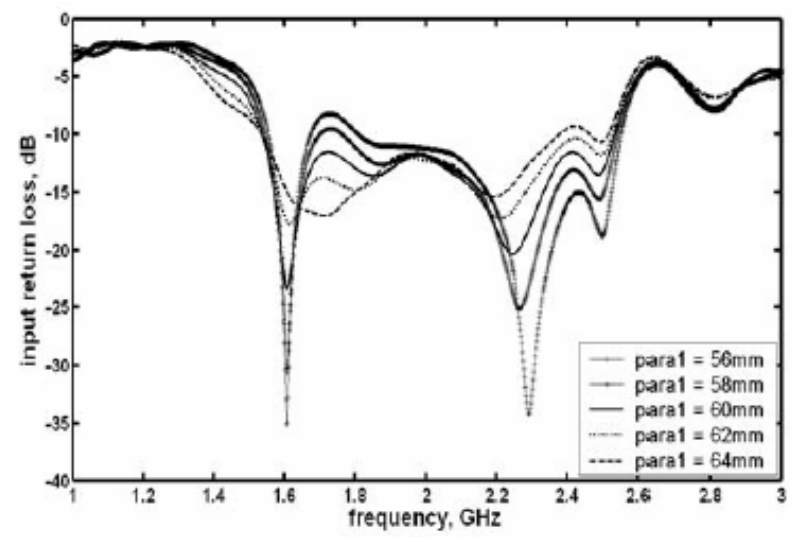

Fig.5. Simulation results of various values of parameter 1

Figure 5 shows the simulation result when Parameter 1 is varied by $2 \mathrm{~mm}$ from $56 \mathrm{~mm}$ to $64 \mathrm{~mm}$. Clearly, the change of $\boldsymbol{L}_{d r i}$ makes the input return loss change unpredictably. Based on this result, it can be stated that the length of driver element affects not only the impedance bandwidth but also the center frequency. As observed, the value of $60 \mathrm{~mm}$ is really the best one. Furthermore, the obtained gain is also sensitive to this parameter. The change of the gain is right proportional to the change of $L_{d r i}$. It means that the obtained gain covresponding to the driver's length of $64 \mathrm{~mm}$ is the highest one.

\section{B. Parameter 2 - $L_{\text {dir }}$}

First, before evaluating the effect of this parameter, we will study the function of two directors on the operation of the antenna. Now, we get rid of the appearance of both two director elements. Figure 6 shows that the bandwidth of the antenna without director is slightly smaller than that of the antenna with one director. Thus, it is acceptable that the bandwidth is nearly unchangeable. From this experiment, we can state that these parasitic elements have no big influence on the width of the impedance bandwidth. In fact, the directors just affect the antenna's gain. Indeed, the gain of an antenna without directors is approximately 2.3
$\mathrm{dBi}$, while the antenna with one director can get the gain of $5.1 \mathrm{dBi}$. This evidence explains the appearance of directors in the antenna.

Next, we will consider the number of directors which we should add in the antenna. We stimulated four antenna models with different number of directors as following: one model with no director, one model with one director, one model with two directors, and one model with five directors (fig 7). Figure 8 shows simulation results of return loss of the antenna models. As mentioned above, the bandwidth of the antenna without director is slightly the same as that of the antenna with one director, but resonant frequencies slide towards higher values. The bandwidth of the latter antenna does not meet our expectation that it covers $1.575 \mathrm{GHz}$ of GPS band. Thus, we cannot use this model.

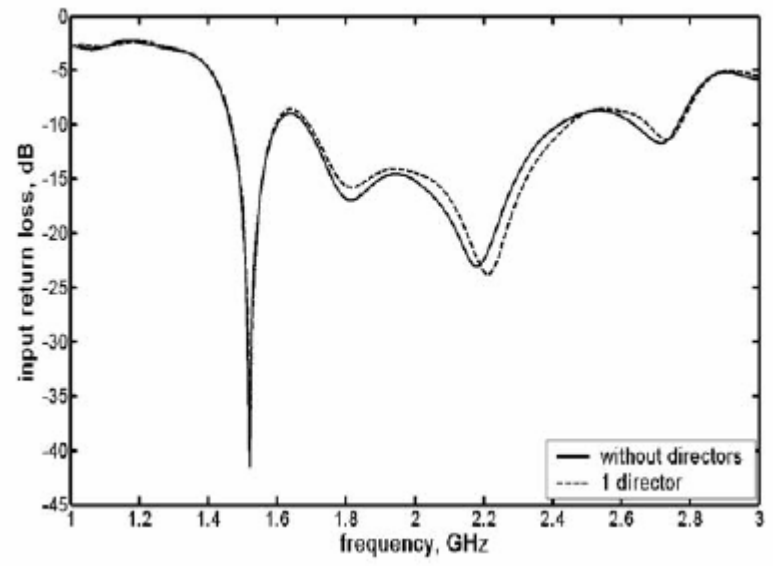

Fig.6. Comparing the antenna without director to the antenna with one director

As seen in Fig. 8, the antenna with two directors has a bandwidth covering required frequencies and a gain of $6.2 \mathrm{dBi}$. This model has not only characteristic of bandwidth antenna, but also high directivity. They are advantages that an ordinary Yagi antenna lacks.

Next, we can see simulation result of the antenna with five directors. Indeed, this antenna has prominent broad bandwidth than other models. Furthermore, its gain is $6.7 \mathrm{dBi}$. This fact is explainable. According to principle of a Yagi antenna, when the number of 
directors increases, the bandwidth increases too. Nevertheless, in contrast to these advantages, this model is so complicated to manufacture and it does not radiate effectively. In fact, its effectiveness is $76 \%$ while the antenna with two directors has a radiation effectiveness of $79 \%$. Thus, the antenna with two directors is the most perfect choice with a high gain, broad bandwidth, and high radiation effectiveness.

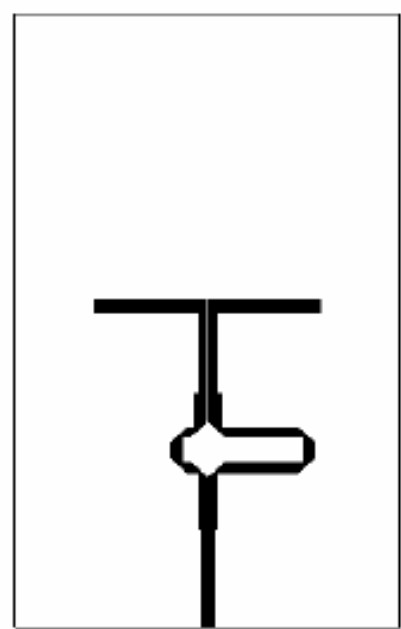

(a) None director

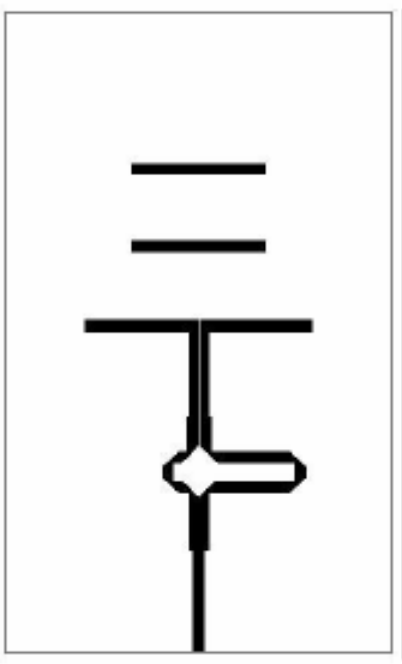

(c) Couple of directors

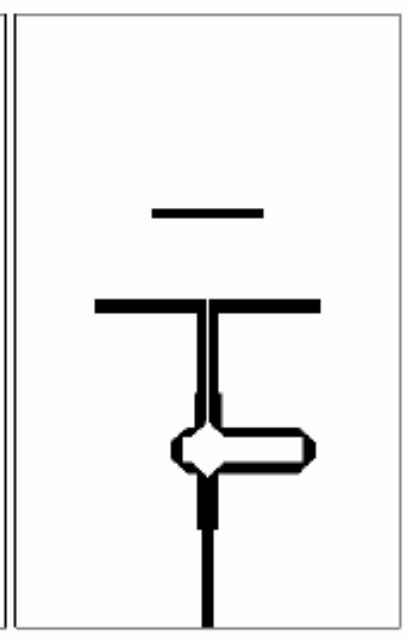

(b) Single director

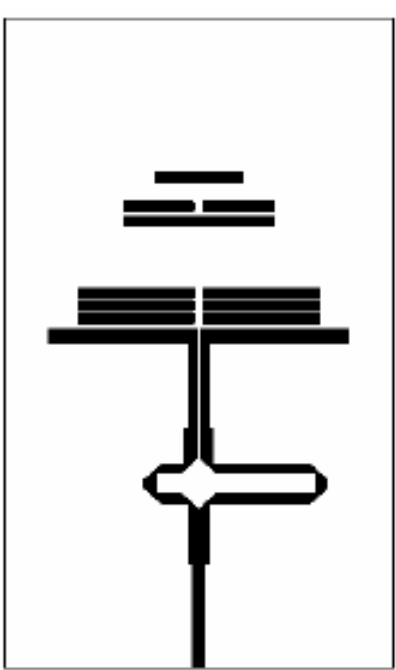

(d) Complex directors
Fig.7. Antenna models with different directors



Fig.8. Simulation results of antenna models with different directors

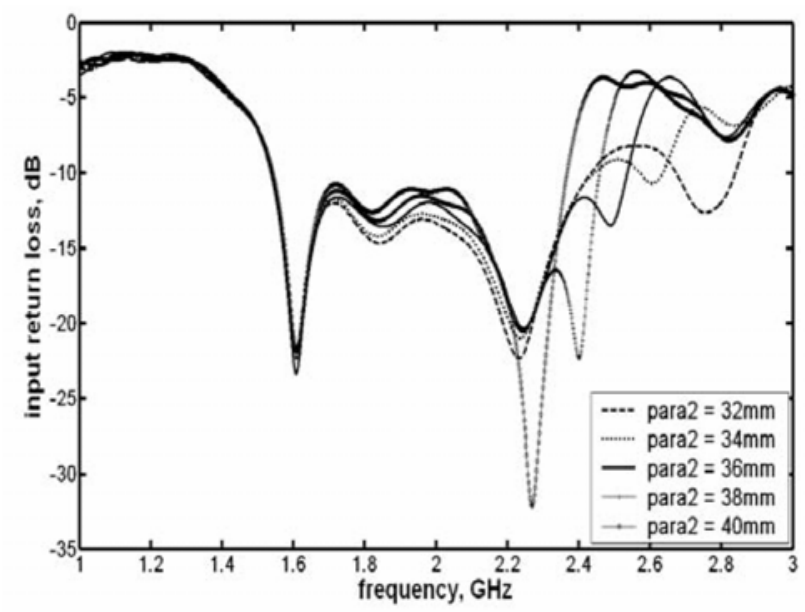

Fig.9. Simulation results of various values of parameter 2- $L_{\text {dir }}$

Finally, we put two directors again in the designed antenna to test the effect of $\boldsymbol{L}_{\text {dir }}$. Figure 9 shows the result when Parameter 2 is varied by an increase of step $2 \mathrm{~mm}$, from $32 \mathrm{~mm}$ to $40 \mathrm{~mm}$. As observed, this parameter changes the positions of the lowest and highest resonant frequencies in the band. The fact is that when we extend the length of directors, the resonant frequencies will have high values. Conversely when the Parameter 2 is shortened, the antenna will resonate at 
low frequencies. As a result, the center frequency is affected by Parameter 2.

This plot might make readers confuse, because observed results demonstrate that directors changed the impedance bandwidth of the antenna. These results seem to cast doubt on the statement. However, the fact is that directors are passive elements, so when we extend the length of directors $\boldsymbol{L}_{\text {dir }}$, we must expand the space between the driver and the nearest director $S_{\text {dir }}$ appropriately. If the correlation between $L_{\text {dir }}$ and $S_{d i r}$ is unchangeable, the bandwidth will remain. In this experiment, $\boldsymbol{L}_{\text {ditr }}$ is changed, while $\boldsymbol{S}_{\text {dit }}$ remains. Thus, the fact that the bandwidth is changed can be understandable.

\section{Parameter $3-S_{6}$}

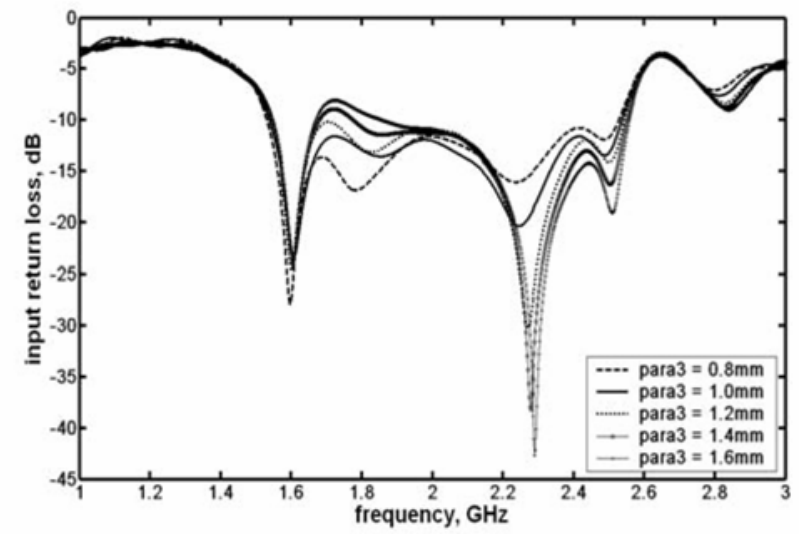

Fig. 10. Simulation results of various values of parameter $3-S_{6}$

Figure 10 shows the result when we change Parameter 3 with the step of $0.2 \mathrm{~mm}$ from $0.8 \mathrm{~mm}$ to $1.6 \mathrm{~mm}$. Obviously, Parameter 3 is not a parameter affecting the bandwidth as well as the center frequency. However, the result reveals that the input return loss degrades when the gap is reduced. In fact, when the gap is widened, the return loss at low frequencies also goes up, while this value at high frequencies goes down. This image looks like the operation of a lever. Thus, it is necessary to make a balance between the return loss of low frequencies and high frequencies. In Fig. 8, the value of $1 \mathrm{~mm}$ meets this requirement, so it becomes an ideal choice for Parameter 3.

\section{Parameter $4-S_{\text {dir }}$}

In Fig. 11 Parameter 4 was varied by $2 \mathrm{~mm}$ from 16 $\mathrm{mm}$ to $24 \mathrm{~mm}$. This simulation result indicates that $S_{\text {ditr }}$ has no influence on the antenna's bandwidth as well as the return loss. As mentioned in the previous section, this parameter has a special relationship with the length of directors. Truly, they restrain each other. Through experiments, the couple values $\mathrm{S}_{\mathrm{dir}}=20 \mathrm{~mm}$ and $\mathrm{S}_{\mathrm{dir}}=$ $36 \mathrm{~mm}$ were chosen because of their excellent performance.

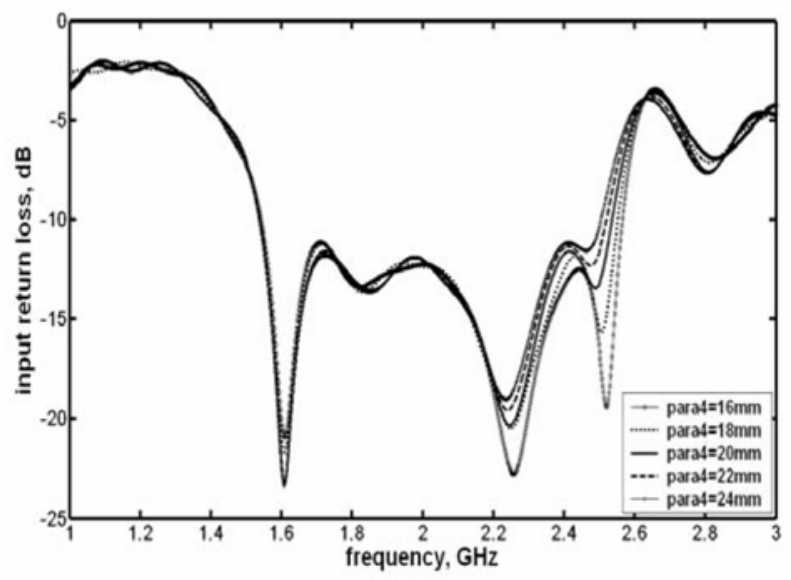

Fig.11. Simulation results of various values of parameter $4-S_{d i r}$

\section{E. Parameter $5-S_{\text {reff }}$}

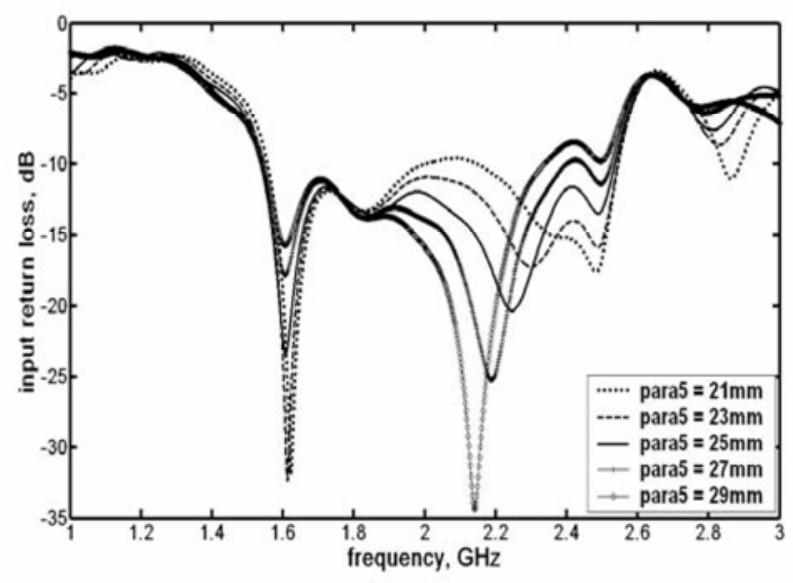

Fig.12. Simulation results of various values of parameter $5-\mathrm{S}_{\mathrm{r} \text { ef }}$ 
Figure 12 shows results when Parameter 5 is varied by $2 \mathrm{~mm}$ from $21 \mathrm{~mm}$ to $29 \mathrm{~mm}$. Indeed, the bandwidth is not really sensitive to Parameter 5. However, when the distance between the driver and the reflector increases, the return loss will degrade. It is totally logical, because this phenomena is the same as the phenomena when you throw a ball against the wall. The more the distance, the less the reflection's power. As observed, in these five values, the value of $25 \mathrm{~mm}$ brings the best result.

\section{F. Parameter 6 - $\mathrm{L}_{5}$}

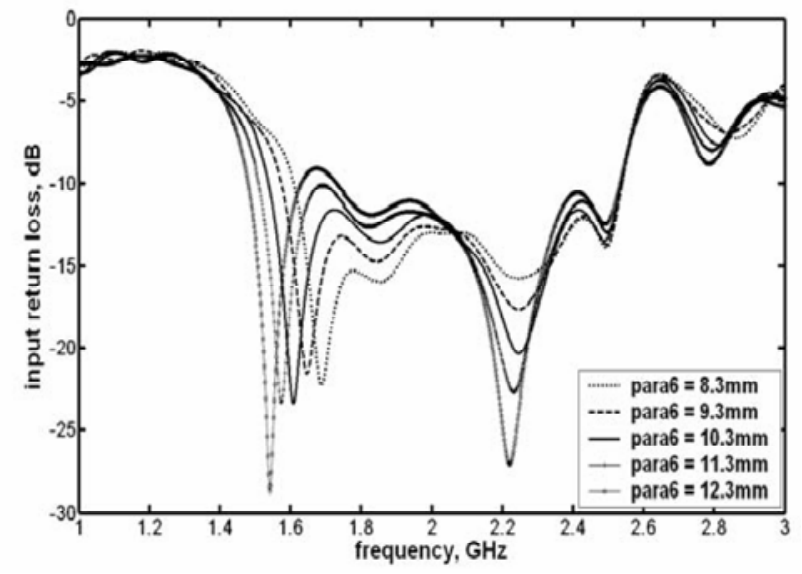

Fig.13. Simulation results of various values of parameter $6-L_{5}$

The fact is that not many people concern and study this parameter. In [5] or [9], there are five parameters mentioned as the main factors in designing a quasiYagi antenna. However, through experiments and studies, $\boldsymbol{L}_{5}$ has demonstrated its importance in rectifying the bandwidth. This parameter is the length of the two parallel strip-lines of the top of the balun. Therefore, it also contributes to the operation of the balun. As mentioned in Section II.A, the balun must match impedance between microstrip access line and the CPS [10]. Consequently, this parameter affects the impedance bandwidth, which is reasonable.

In Fig. 13, there are five curved lines for five values of Parameter 6 from $8.3 \mathrm{~mm}$ to $12.3 \mathrm{~mm}$.

The results divulge that when $\boldsymbol{L}_{5}$ increases, the bandwidth is expanded and the return loss is upgraded.
Since, the desirable result needs to have a broad bandwidth, but a low return loss, the value of $10.3 \mathrm{~mm}$ is the best choice to meet requirements.

\section{G. Parameter 7- $L_{4}$}

This parameter is the length of two arms of the balun. Thus, like Parameter 6, it plays a role in supplementing the operation of the balun. Figure 14 shows the results when Parameter 7 was varied by $1 \mathrm{~mm}$ from $4 \mathrm{~mm}$ to $8 \mathrm{~mm}$. As observed, this plot is similar to the plot in Fig. 13, which means the role and effect of Parameter 7 is the same as of Parameter 6 (see in the above section). According to the explanation in the previous section, the value of $6 \mathrm{~mm}$ is the best choice for Parameter 7.

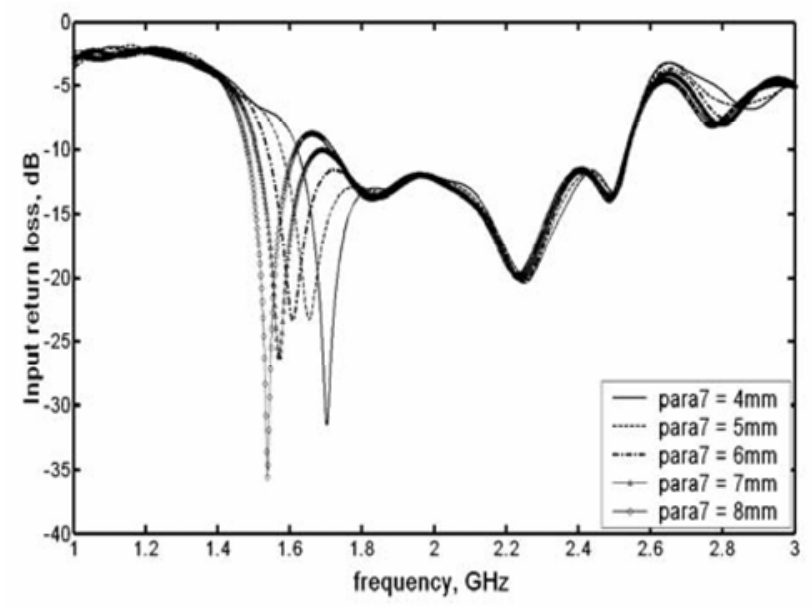

Fig.14. Simulation results of various values of parameter $7-L_{4}$

Note: both Parameter 6 and Parameter 7 need to be chosen carefully to achieve a $180^{\circ}$ phase difference between both strips of the CPS. It is because the further the phase difference is from $180^{\circ}$, the worse the excitation of the odd mode in the CPS, which changes co-polar radiation pattern and degrades the cross-polar level [10].

\section{MESUREMENT RESULTS}

Figure 15 shows the fabricated antenna on FR4. Figure 16 shows the input return loss measurement result of fabricated antenna. Comparing to the 
simulation result, this result has a little difference and it seems to shift towards higher frequencies. The difference is resulted from some causes. First, the dielectric value of the substrate is not the same as these of ideal substrate. Second, the dimensions of a fabricated antenna are little different from the designed one. Finally, in process of measuring, the measurer made some flaws, or there are some mistakes of a machine. However, the measurement result is acceptable.

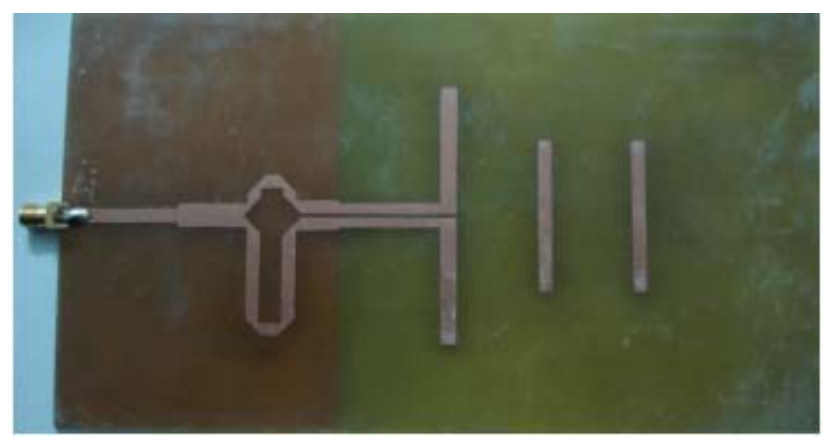

Fig.15. Realized antenna on FR4

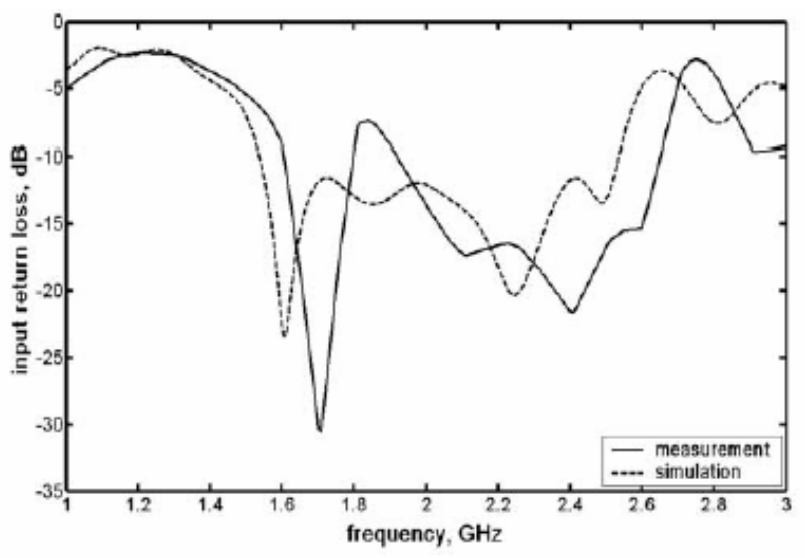

Fig.16. Input return loss of fabricated UMTS quasiYagi antenna

\section{CONCLUSION}

In this paper, we develop in deep a micro-strip fed planar quasi-Yagi antenna designed for UMTS systems using substrate FR4 which achieves broadband and good radiation characteristics. Especially, the fabricated antenna obtains these advantages as well. In addition, we investigate the effect of each dimension of the antenna on its operation. We find out that the driver element has a big influence on the bandwidth as well as the operation of the antenna, while directors on antenna can improve its directivity and resonant frequencies. The width of the gap is proportional to the input return loss, but has no effect on the bandwidth. Notably, when designing a quasi-Yagi, we should care for the coplanar because it affects both the bandwidth and the input return loss. This antenna could be applied widely to next generation communication systems at various operating frequencies. In other words, it can be utilized in multi band and multi-mode wireless communication systems.

\section{REFERENCES}

[1] Y.Quian, W.R.Deal, N.Kaneda and T.Itoh, "'Mircostripfed quasi-Yagi antenna with broadband characteristics," IEEE Trans, Antenna and Propagat, vol.50, no.8, pp, 1158-1160, Aug, 2002.

[2] Kaneda, N; Deal, W.R.; Yongxi Quian; Waterhouse, R.; Itoh, T., "A broad-band Quasi-Yagi antenna," IEEE Trans.on antennas and propagation, Vol.50, No.8, August 2002.

[3] H.K.Kan, R.B.Waterhouse, A.M.Abosh and M.E.Bialkowski "Simple Broadband planar CPW-fed quasi-Yagi antenna" IEEE Antennas and Wireless Propagat, Lett., vol. 6, pp. 18-20,/2007.

[4] L.C.Kretly, and Alex S.Riberio, "A novel Titled dipole Quasi-Yagi antenna designed for $3 \mathrm{G}$ and bluetooth Applications", Microw, and Optoelectronics Conf., vol.1, pp. 303-360, Sep, 2003.

[5] C. L. Yeo, "Thesis of Active microstrip array antennas," The school of computer science and electrical engineering, University of Queensland, Oct 2000.

[6] W. R. Deal, N. Kaneda, J. Sor, Y. Qian and T. Itoh, “A new quasi-Yagi antenna for planar active antenna arrays," IEEE Trans. Microwave Theory Tech., vol. 48, no. 6, pp. 910-918, Jun. 2000.

[7] C. A. Balanis, "Antenna Theory: Analysis and Design," 2nd edit., Wiley1982.

[8] K. F. Lee and W. Chen, "Advances in microstrip and printed antenna," Wiley 1997.

[9] Hyok J. Song, Marek E. Bialkowski, "Investigation into the operation of a microstrip-fed uniplanar quasi-Yagi antenna," IEEE press 2000.

[10] V. C. Gracia, R. Casaleiz, E. Mrquez-Segura, P. Otero, C. C. Pealosa, "Balun effects in the quasi-Yagi antenna," IEEE Melecon, 2006.

[11] Y Qian,W. R. Deal, N. Kaneda, T. Itoh, "Mutual coupling and mitigation in two-dimensional phased arrays based on planar quasi-Yagi antenna," ARO MURI 
DAAH04-96-1-0005 and Rockwell Science Center MIRCO

\section{AUTHOR'S BIOGRAPHY}

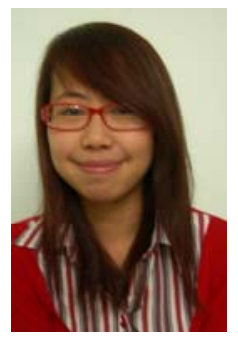

Mai Thanh Nga, a five-year student in Faculty of Electronics and Telecommunications, Hanoi University of Technology. Her major is Telecommunications; especially she focuses on studying wireless communication systems and optical communications. Her main interests include studying antennas, computing spectral estimation algorithms, and developing digital signal processing. In fact, she has implemented some projects on designing and manufacturing antennas, such as GPS, UWB, and UMTS. Currently, she is doing her thesis research on MIMO antennas applied for Cognitive Radio systems. Also, she wants to incorporate this topic into her Master's thesis in the future.

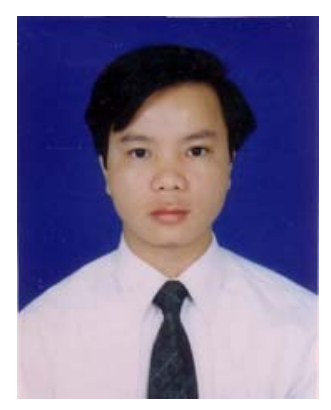

Dr. Vu Van Yem received the Ph.D. degree in communications from the Department of Electronics and Communications, TELECOM ParisTech (formerly ENST Paris) France in 2005. From 2006 to 2007, he was a postdoctoral researcher at the Department of Hyperfrequencies and Semiconductor, Institute of Electronics, Microelectronics and Nanotechnology (IEMN), CNRS(Centre National de la Recherche Scientifique). He is currently the head of the department of telecommunication systems, faculty of Electronics and Telecommunications, Hanoi University of Technology.

Dr. Vu Van Yem's areas of expertise are ultra wide band communication and localization techniques, antenna and propagation technologies and satellite communications. He is member of the IEEE, REV and reviewer of several wellknown national and international professional journals and conferences.

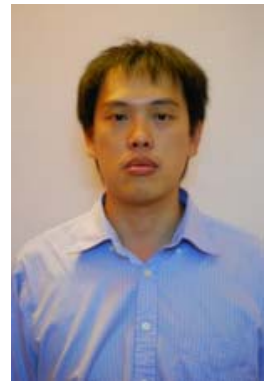

Dr. Nguyen Huu Thanh received Bachelor and Master degree in Electrical Engineering from Hanoi University of Technology and earned Ph.D degree in Computer Science from the University of Federal Armed Forces Munich, Germany in 2002. From 2002 to 2004, he worked at Fraunhofer Institute FOKUS Berlin in the Competence Center of the Next Generation Network Infrastructure. Since 2004 he has been working at Hanoi University of Technology and is the Vice-Dean of the Faculty of Electronics and Telecommunications since 2005. Dr. Nguyen Huu Thanh's research interests are QoS architecture and mechanisms in back-bone and access networks, including wireless networks; architecture for value-added services in all-IP networks; performance evaluation of communications networks and ad-hoc/sensor networking. Currently he leads some international and national research projects on these areas. He is the member of IEEE ComSoc and is reviewer of several well-known national and international professional journals and conferences.:



Pham Huy Phong received the B.E degree in Telecommunications Engineering from University of Communications and Transport, Hanoi, in 2000 and the Master degree from Hanoi University of Technology, Hanoi, Vietnam in 2007. He is currently working toward the Ph.D degree in the Telecommunications Engineering at

Vietnam Research Institute of Electronics, Informatics and Automation, Hanoi, Vietnam.

$\mathrm{He}$ was a researcher in Posts and Telecommunications Institute of Technology (2000-2005). He is the Vice-Dean of the Faculty of Electronics and Telecommunications and Vice Director of the Center for Research and Consulting in Telecommunications at the Electric Power University, Hanoi, Vietnam. His current research interest is wireless communications. 